Features

\section{A Novel Biomechanical Analysis of Horticultural Digging}

\author{
James Shippen ${ }^{1,3}$, Paul Alexander ${ }^{2}$, and Barbara May ${ }^{1}$
}

AdDITIONAL INDEX wORDs. musculoskeletal modeling, joint torques, joint contact forces, motion capture, injury prevention, optical tracking, magneto-inertial tracking

SUMMARY. Musculoskeletal injuries are commonly reported in workers employed in labor-intensive agricultural-type tasks. A novel method of determining joint angles, joint torques, and contact forces, using three-dimensional motion capture and musculoskeletal modeling, was applied to the movements of a sample of workers, engaged in the horticultural task of digging, to determine if objective biomechanical data could be correlated with a subjective visual assessment to predict risk of injury. The joint angle time histories of horticulturists were calculated from the motion capture data, and this was used to articulate a musculoskeletal model of the subjects. The joint torques were calculated using inverse dynamics methods from which the individual muscle loads were established using a cost function minimization approach. Finally, the joint contact forces were calculated including the muscle forces. The motion capture data of digging trials were observed by a team of horticulturists and physiotherapists who categorized each of the observed trials according to form, efficiency, and risk of injury. Trials demonstrating techniques which were more likely to yield injuries were identified as "examples of bad technique"; those judged to be less likely to yield injuries were categorized as "examples of good technique." It was found that the joint torques and contact forces and their variability were lower in the trial which was identified as good technique, and consistently higher in the examples of bad technique. The results of the study suggest that measurement of joint angles, joint torques, joint contact forces, and forces in the muscles could serve as a valuable tool to develop training programs for horticultural workers engaged in certain high intensity tasks, such as digging, to effectively improve efficiency and reduce incidence of injury. It may also be possible to modify horticulture-related equipment to minimize the internal loads within the body to reduce the risk to health and, therefore, extend active participation in horticulture.

S ignificant numbers of people engage in gardening as a popular pastime (Dunnett and Qasim, 2000; Sommerfield et al., 2010) or are employed in the wider horticultural industry (e.g., landscaping). The practice of gardening has been described as a moderately rigorous form of exercise (Armstrong, 2000) and the musculoskeletal demands of gardening are considered substantial (Knibbs, 2014).

Much work has been done in establishing the "intensity" of exercise which certain tasks offer to attribute value in an exercise context (Park et al., 2008). Common gardening tasks which use the upper and lower body such as digging and raking are described as having moderate intensity, whereas tasks which mainly use the upper body such as transplanting seedlings and hand weeding are classified as low intensity in those aged more than 65 years (Park et al., 2008, 2011). With an increased interest in the use of gardening as a form of exercise and a health intervention (Galloway and Jokl, 2000; Park and Shoemaker, 2009; Park et al., 2008, 2011, 2017; Sommerfield et al., 2010), it would appear that gardening has potential to be beneficial for all (Etheredge et al., 2016). However, it is important to recognize that as with any exercise, the risk of injury associated with gardening tasks (Park and Shoemaker, 2009), and more specifically digging (Bridger et al., 1998), is of concern. Detailed data on reported injuries (and economic loss) associated with horticultural digging are difficult to capture. Professional horticulture is a relatively fragmented industry consisting of largely self-employed workers or small businesses, and this can lead to under reporting of accidents and injuries (Solomon et al., 2007). Accurate data collection is further complicated by the fact that musculoskeletal disorders are difficult to associate with particular repeated activities (Schneider, 2001). However, a survey carried out in the Netherlands of 2580 male employees and employers in Dutch agriculture reported that a total of $75 \%$ of the employees and $71 \%$ of the employers suffered from musculoskeletal symptoms, predominantly in the lower back, followed by the neckshoulder and knees (Hildebrandt, 2007). Within amateur horticulture, data collection becomes even more difficult to coordinate and capture. However, several studies considering horticulture as a form of exercise report gardeners associating gardening (and digging in particular) with lower back pain (Buck, 2016; Park and Shoemaker, 2009). By better understanding the biomechanics of digging, it may be possible to reduce the risk of injury through improved advice, training, and awareness raising.

As understanding of the musculoskeletal system develops, as well as the ability to monitor and measure forces and torques using biomechanical analysis, the impact of digging on different musculoskeletal components is easier to measure. Early research on ergonomics and biomechanics associated with manual handling type tasks used observational studies (Buchholz et al., 1996), and as technology developed, quantitative bioinstrumentation was introduced (Marras et al., 1993) as well as three-dimensional motion capture and musculoskeletal modeling (Winter, 2004). The application 
of biomechanical analysis in the measurement of clinical gait is now a mature procedure (Patrick, 1991). Accordingly, the quality and validity of the data has enabled its use in pre- and postoperative evaluation (Perron et al., 2000 ) and for non-invasive anthropometric measurement (Shippen and Ashford, 2003).

More recently, biomechanical analysis was adopted by sports studies to objectively measure performance and compare actions between athletes to optimize performance and to develop techniques which minimize the risk of injury. Examples of applications include weight lifting (Lauder and Lake, 2008), throwing events (Nissen et al., 2007), wheelchair tennis (Reid et al., 2007), cycling, rowing, track and field events (Tilp et al., 2008), and boxing (Filimonov et al., 1983). Moreover, there is evidence that high joint torques have a positive correlation with injury risk (Sun et al., 2015).

Horticulture is also suitable for analysis where the primary objectives may be injury avoidance and increasing the efficiency of the participant in gardening tasks. Abnormal patterns of gardening movement may be selfsustaining and reinforced over time by repetition and be the cause of potential injury risk. It is known that muscle fatigue reduces the force capabilities of a muscle (Lieber and Friden, 1988) and that excessive force magnitudes or repetitious forces may surpass the capacity and recovery limits of muscles which may result in fatigue or injury. Medical and healthcare practitioners therefore need to understand the kinematics and kinetics of gardening movement to enable them to facilitate improvement of movement performance, reduce or prevent injury, or if injuries are present, to identify a therapeutic regime to support rehabilitation (Lehmkuhl and Smith, 1988).

We would like to thank Leslie McBride, Sean Lowton-Smith, Leigh Hunt, Rebekah Mealey, and Nick Morgan for their contribution to the assessment of the trials

${ }^{1}$ Centre for Mobility and Transport, Coventry University, Coventry, CVI 5FB, United Kingdom

${ }^{2}$ Royal Horticultural Society, Wisley, Woking, GU23 6QB, United Kingdom

${ }^{3}$ Corresponding author. E-mail: j.shippen@coventry. ac.uk.

This is an open access article distributed under the CC BY-NC-ND license (http://creativecommons.org/ licenses/by-nc-nd/4.0/).

doi: 10.21273/HORTTECH03800-17
To undertake a biomechanical analysis of a horticultural action requires data about the movement of the subject, or subjects, and the external forces being applied on them. Forces are pushes and pulls which cause an object to accelerate unless restrained by counteracting forces. Torques are the rotational equivalent of forces; torques cause objects to rotate (Serway and Jewett, 2003). For example, to drive a screw into wood, the hand applies a torque to the screwdriver which applies a torque to the screw; the body moves due to the locomotor muscles around the body applying torques at the joints. Biomechanical analysis can assist in the understanding of the forces and torques at work within the gardener's body during horticultural tasks (Shippen and May, 2012).

The three-dimensional movement of the subject is typically measured in one of two ways: optical tracking or magneto-inertial tracking. Optical tracking requires the attachment of retro-reflective markers to the subject in the Helen Hayes marker set (Hallemans et al., 2005.) at anatomical landmarks (Fig. IA shows an example of an optical tracking system). The subject is then surrounded by numerous cameras, typically 12-15. Attached to each camera is a light source and the camera records the motion of the markers by observing the reflected light (the subject is not seen). Each camera produces a two-dimensional image of the scene; however, by combining multiple images from the differing locations of all of the cameras, a three-dimensional representation can be constructed. Optical tracking has the advantage of measuring absolute positions with a high level of accuracy, normally better than $\pm 1 \mathrm{~mm}$. However, the disadvantages of optical tracking include a sensitivity to high ambient light (often excluding working outside) and a requirement for extensive post-processing after the data collection to clean the data.

Magneto-inertial tracking requires the attachment of sensors to segments of the body, typically 17 segments (Shippen and May, 2016). Figure $1 \mathrm{~B}$ shows an example of a magneto-inertial system. Within each sensor are three linear accelerometers, three gyroscopes, and three magnetometers. Doubly integrating the linear acceleration returns linear displacement and integrating the angular velocity from the gyroscopes returns the orientation of the segment. The linear and angular drifts inherent in the integrations can be removed using the magnetometers, gravitational direction, and contact conditions (Karatsidis et al., 2017). The measurement of absolute position is not as good using magneto-inertial as it is with optical tracking. However, magneto-inertial tracking has the major advantage in a horticultural setting of being able to be used outside.

Digging is taken as an exemplar of an activity suitable for biomechanical analysis in the identification of techniques and postures which can be advantageous and disadvantageous for the maintenance of optimal health. Although the ergonomics of manual handling and the impact of power tools, and in some cases manually powered tools, have been studied, little work has been done on digging and its suggested detrimental effects on the musculoskeletal system of the user, specifically the lower back (Bridger et al., 1997, 1998). The purpose of this study is to apply motion capture techniques and novel musculoskeletal modeling techniques commonly used in clinical and sporting environments to analyze the loads in the joints and muscles of gardeners. By focusing on digging initially, this research will examine a common gardening task that is considered to be of moderate intensity and perceived to be potentially harmful to the body.

\begin{tabular}{llll}
\hline $\begin{array}{l}\text { Units } \\
\text { To convert U.S. to SI, } \\
\text { multiply by }\end{array}$ & U.S. unit & SI unit & $\begin{array}{l}\text { To convert SI to U.S., } \\
\text { multiply by }\end{array}$ \\
\hline 0.3048 & $\mathrm{ft}$ & $\mathrm{m}$ & 3.2808 \\
3.7854 & $\mathrm{gal}$ & $\mathrm{L}$ & 0.2642 \\
25.4 & inch(es) & $\mathrm{mm}$ & 0.0394 \\
0.4536 & $\mathrm{lb}$ & $\mathrm{kg}$ & 2.2046 \\
4.4482 & $\mathrm{lbf}$ & $\mathrm{N}$ & 0.2248 \\
1.3558 & $\mathrm{lbfft}$ & $\mathrm{N} \cdot \mathrm{m}$ & 0.7376
\end{tabular}




\section{Materials and methods}

The torques that occur at the joints during any activity can be calculated using inverse dynamics techniques (Crowninshield et al., 1978). For an open loop hierarchy, the calculation of the torques at the joints can be obtained from

$$
\boldsymbol{T}=\sum_{i=1}^{n} I_{i} \boldsymbol{\alpha}_{i}+\sum_{i=1}^{n}\left(\boldsymbol{r}_{i} \times\left(f_{i}-m_{i} \boldsymbol{x}_{i}\right)\right) \text {. }
$$

where $T$ is the torque vector at the joint; $n$ is the number of segments distal to the joint; $I_{i}$ is the inertia tensor of the $i$ th segment distal to the joint; $\boldsymbol{\alpha}_{i}$ is the angular acceleration vector of the $i$ th segment distal to the joint; $r_{i}$ is the position vector of the $i$ th segment distal to the joint relative to the joint; $f_{i}$ is the external force applied to the $i$ th segment distal to the joint; $m_{i}$ is the scalar mass of the $i$ th segment distal to the joint; and $\boldsymbol{x}_{i}$ is the acceleration of the $i$ th segment distal to the joint in the global coordinate system.

The force of constraint at the joint is

$$
\boldsymbol{F}=\sum_{i=1}^{n}\left(f_{i}-m_{i} \boldsymbol{x}_{i}\right)
$$

where $F$ is the force of constraint vector at the joint.

The external forces which act on the subject normally occur between the person and the tools which are being used in the task. The measurement of these forces generally requires the introduction of a force transducer into the tool. However, there are some tasks for which the force can be readily calculated (e.g., lifting a known weight of soil on a spade).

The torques at the joints were generated by the contraction of the muscles which cross the joint (Fig. 2A). Eq. [1] was used to calculate the torques occurring at the joints of the body during arbitrary horticultural tasks and Eq. [2] yielded the joint contact forces. However, there is no unique solution for the load distributions within the muscles. This is because there are $\approx 50$ torques at the major joints within the body. There are also $\approx 600$ locomotor muscles (the muscles which cause voluntary movement of the body) which can potentially lead to an infinite number of solutions. This can be demonstrated by considering that simultaneous tensing of antagonistic muscles can cause no motion (e.g., the quadriceps which extend the knee and the hamstrings which flex the knee). Hence, the relaxed and tensed muscle tensions are both valid solutions to the force distribution problem.

To obtain a unique solution to the muscle force distribution problem, an assumption is made about how the neurological system configures the loads within the body. The assumption is that the body tries to generate the observed motion using the minimal possible muscle force (Shippen and May, 2010). This assumption is physiologically justified by noting that this strategy minimizes fatigue (Erdemir et al., 2007). This assumption is quantified as a cost function of the sum of the square of the muscle activations, where the muscle activation is defined as the instantaneous muscle force divided by the maximum isometric muscle force; i.e., the maximum force a stationary muscle can produce. By minimizing the cost function, the muscle force distribution can be calculated (Fig. 2B).

Once the muscle force distribution is established, the total force between the bones meeting at a joint, the joint contact force, can be calculated as the vectorial sum of the forces of constraint and the forces of all of the muscles crossing the joint (Fig. 2C). The energy demand of each muscle can be calculated as the integral of the muscle force with respect to contraction displacement and the power as the integral of muscle force

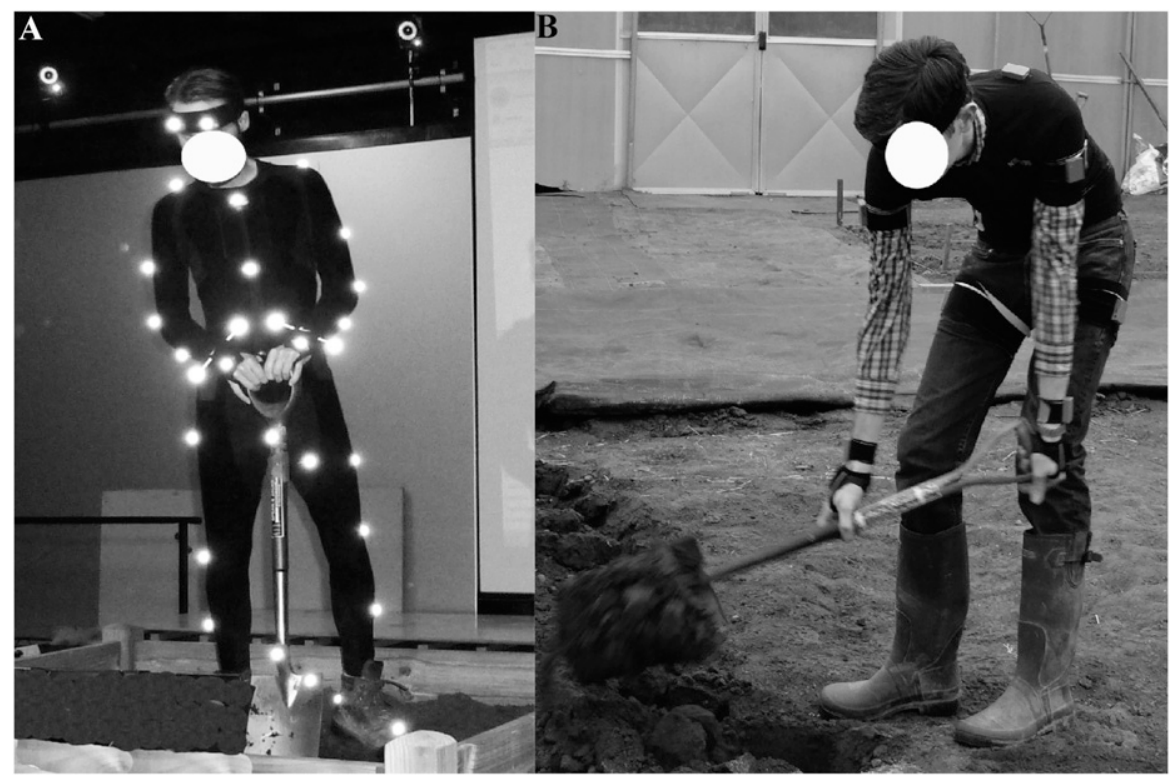

Fig. 1. Three-dimensional motion-capture systems used during digging trials [optical tracking (A), magneto-inertial (B)].

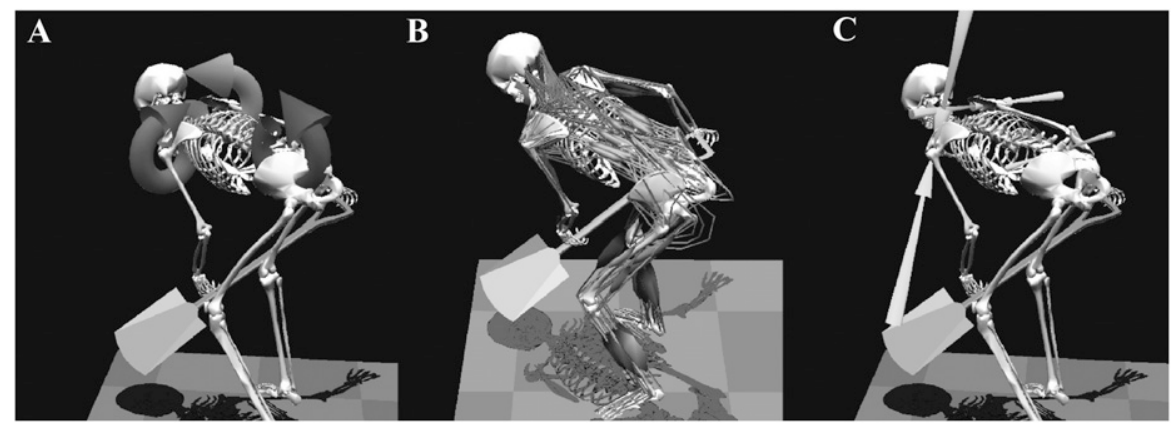

Fig. 2. Examples of torques, muscles forces, and joint contact forces that occur within the body during digging [joint torques (A), muscle forces (B), joint contact forces $(\mathrm{C})]$. 
with respect to contraction velocity. The whole body energy demand and power needed for the task is the summation across all of the locomotor muscles. All the data collected were then analyzed using Biomechanics of Bodies (BoB-Biomechanics, 2016) analysis code written in MATLAB (MathWorks, Natick, MA)a general purpose numerical analysis environment.

As a demonstration of the aforementioned methods, the loads and torques occurring within the joints and muscles of the body were calculated during digging using an inverse dynamics and cost function minimization. A 12-camera optical tracking system (MX40: Vicon Motion Systems, Oxford, UK) was used to measure the movement of 15 subjects [mean $( \pm$ SD) age $=36 \pm 13$ years, age range $=20-72$ years; mean height $=1.72 \pm 0.07 \mathrm{~m}$, height range $=1.58-1.81 \mathrm{~m}$; mean experience $=15 \pm 13$ years, experience range $=1-50$ years; eight male, seven female]. Each subject undertook two trials; each trial consisted of digging out three spade loads of soil and placing them in a pile to one side, resulting in 30 trials in total. These trials were undertaken in the laboratory to utilize the more accurate optical tracking motion capture system. To recreate typical and consistent soil conditions, each subject undertook the task while standing in a large container $(1.25 \times 1.25 \times$ $0.8 \mathrm{~m}$ ) that allowed full freedom of movement. The container was filled with $1000 \mathrm{~L}$ of clay loam soil (35\% clay, $35 \%$ silt, and $30 \%$ sand), and before each subject performed the task, the same member of the supervisory team heeled the soil down in the container to maintain realistic and consistent soil conditions between the digging trials. The task was defined as digging rather than shovelling as it required the subjects to break up and move soil while shovelling tends to only require moving soil (Bridger et al., 1997).

Each subject was asked to dig using a standard UK-style spade with a slightly curved tip and concave blade (Spear and Jackson, Sheffield, UK). This tool is sold as a "digging spade." It has a shaft (top of handle to top of spit) length $730 \mathrm{~mm}$, spit dimensions $180 \times 290 \mathrm{~mm}$, and weight $2.2 \mathrm{~kg}$. The motion data recorded from the three-dimensional motion capture were used to calculate the time histories of the angles of the major locomotor joints. These joint angles were then used to articulate a musculoskeletal model; hence, the height of the subjects was implicitly normalized to a constant. The external forces during lifting the soil were based on the assumption of moving $10 \mathrm{~kg}$ of soil on the spit of the spade.

The identity of the subjects was anonymized using the musculoskeletal model for visualization of the 30 trials which were subsequently examined by a team of four horticulturists and two physiotherapists. The horticulturists and physiotherapists separately reviewed the movement exhibited in all the trials and ranked their relative actions. The team agreed on one trial as an exemplar of good technique against performance criteria of high horticultural and physiological efficiency and low potential injury risk. The team also agreed on one trial which was felt to be horticulturally and physiologically inefficient and demonstrated a high potential injury risk. The former was labeled "good" and the latter was labeled "bad" and these movements were subjected to inverse dynamics analysis.

\section{Results}

Postures observed during the trials which were identified as examples of good and bad techniques by the team of horticulturists and physiotherapists are illustrated in Fig. 3A and $\mathrm{B}$. The activations of the muscles are color-coded: a green muscle has low activation and a red muscle has a high activation with a continuum in between.

JoINT TORQUES. Using Eq. [1], the joint torques were calculated at both shoulders and in the lumbar region of the back for the examples of both good and bad technique in digging. The subjects in both the good technique example and bad

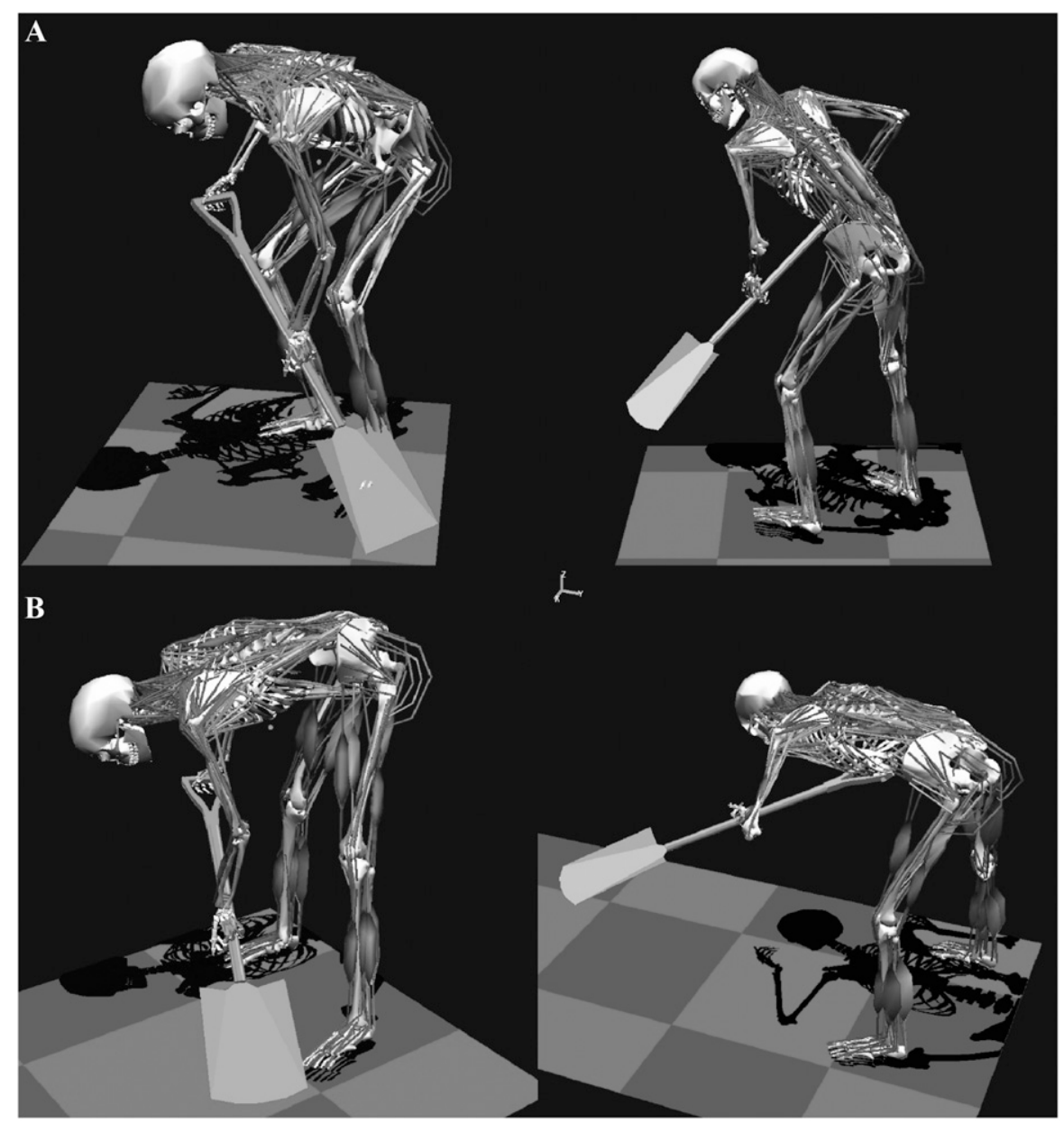

Fig. 3. Examples of postures assessed to be good and bad postures using biomechanical analysis [good posture $(A)$, bad posture $(B)]$. 
technique example were right handed and placed their left hand close to the spade's spit. Therefore, during the lifting of the soil, most of the weight was carried by the left hand and arm, and this resulted in larger torques occurring in the left rather than the right shoulder. The peak torque in the left shoulder was $32 \%$ higher for the bad trial when compared with the good trial (Fig. 4A), and the pattern for the three repetitions was much more consistent in the good trial when compared with the bad trial. In the right shoulder, the peak torque was $15 \%$ higher in the bad when compared with that in the good trial (Fig. 4B), and the pattern was again more consistent across the three repetitions in the good trial, although the bad trial was not as inconsistent as in the left shoulder. The peak torque in the lumbar region of the back was $54 \%$ higher for the bad trial in comparison with the good trial (Fig. 4C). Interestingly, the consistency of the pattern across the three repetitions was better for the good trial and slightly less consistent for the bad trial.

JoINT FORCES. Eq. [2] was used to calculate the constraint forces at the shoulder and in the lumbar region. The forces occurring in the muscles which cross these joints were then vectorially added to the constraint forces to calculate the total joint contact force (Fig. 5). The left shoulder contact force (Fig. 5A) for the bad trial was 30\% higher than the good trial, and the pattern for the three repetitions was much more consistent in the good trial than the bad trial. For the right shoulder (Fig. $5 \mathrm{~B})$, the contact force was $212 \%$ higher in the bad trial when compared with the good trial, but this was an exceptional event and generally the forces are similar. The pattern for the three repetitions was again much more consistent in the good trial than in the bad trial. The lumbar contact force (Fig. 5C) was 47\% larger for the bad trial when compared with the good trial, and again the consistency of the pattern across the three repetitions was higher for the good trial and inconsistent in the bad trial. These results are specific to the subjects studied in the trials and the small number of subjects limits the generalization of these results.

\section{Discussion}

It was found that the approach of applying inverse dynamics methods, followed by cost function minimization,
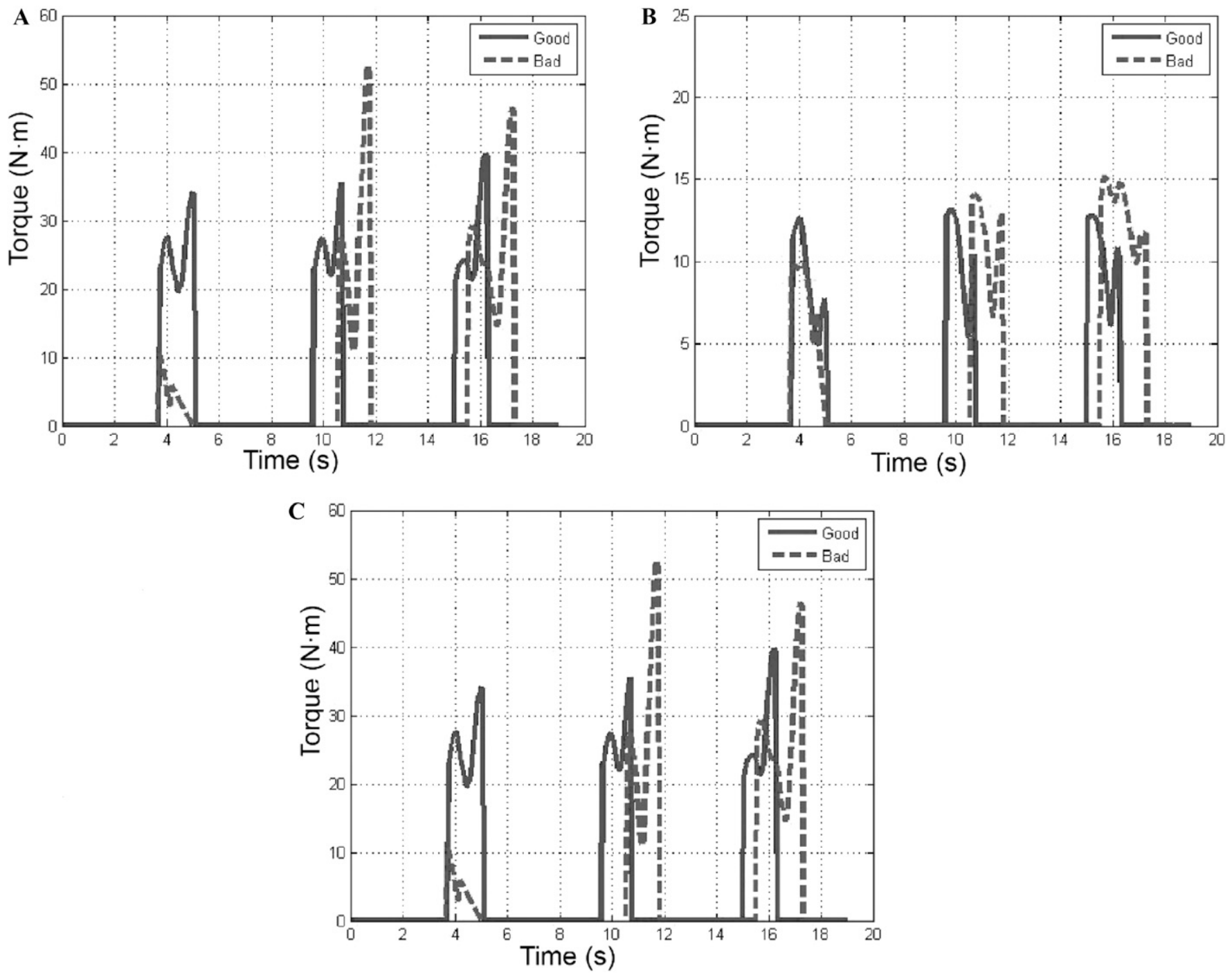

Fig. 4. Comparison of torques for good and bad trials rated on whole body score [left shoulder torque (A), right shoulder torque (B), lumber torque (C)]; $1 \mathrm{~N} \cdot \mathrm{m}=0.7376 \mathrm{lbf} \mathrm{ft}$. 

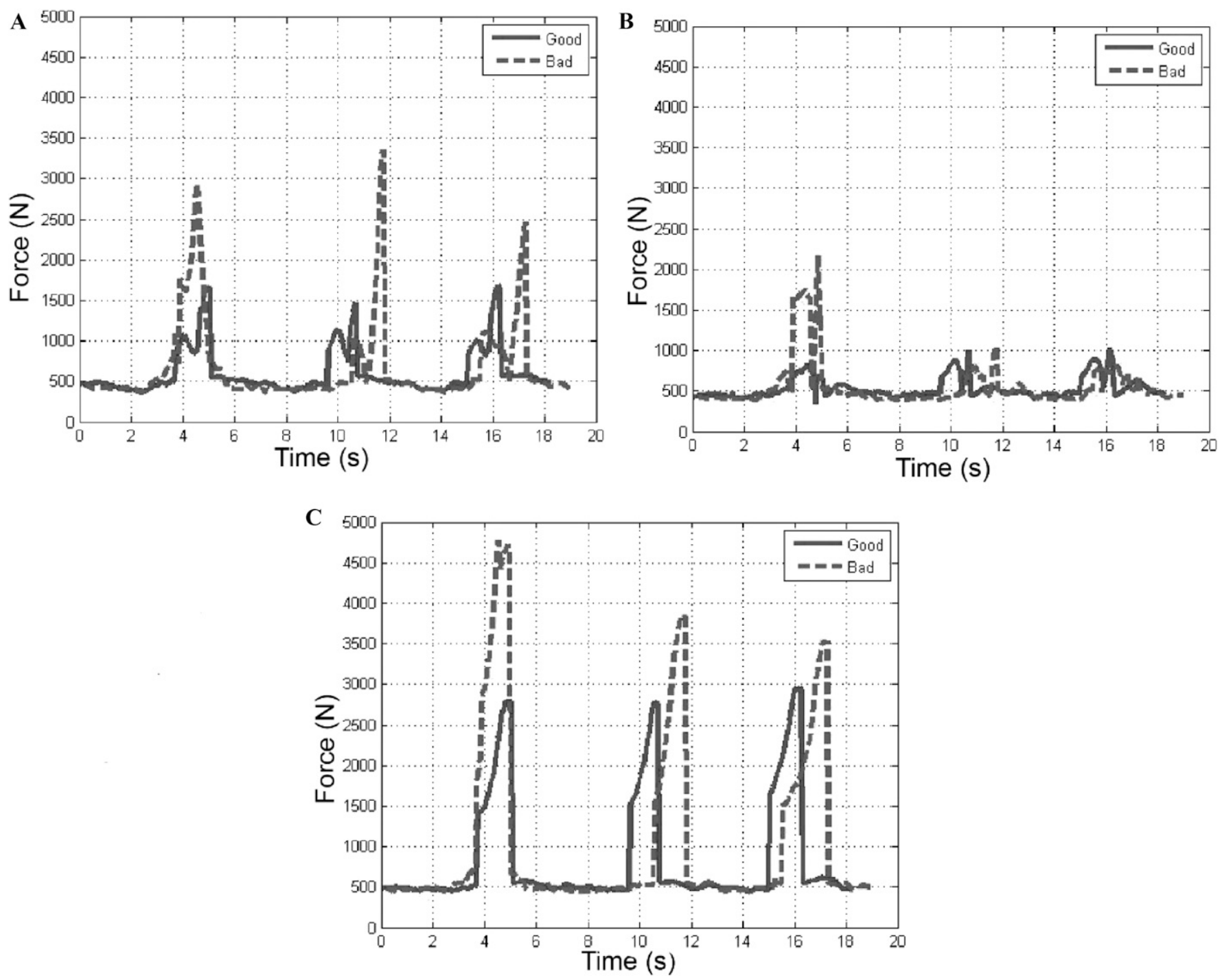

Fig. 5. Comparison of forces for good and bad trials rated on whole body score [left shoulder force (A), right shoulder force (B), lumber force (C)]; $1 \mathrm{~N}=\mathbf{0 . 2 2 4 8} \mathrm{lbf}$.

was a practical technique to calculate the torques and joint contact forces within the joints and muscles of the body during typical horticultural digging tasks.

The modest external force of lifting $10 \mathrm{~kg}$ of soil (about $100 \mathrm{~N}$ ) resulted in a peak force of $3410 \mathrm{~N}$ in the left shoulder joint (glenohumeral) and the intervertebral force was $4744 \mathrm{~N}$ in the lumbar region (L4/L5). These large internal forces occurred because the weight of the soil was acting at a distance comparable to a meter, whereas the muscles were acting at a lever arm comparable with millimeters. For a given torque, as the lever arm decreases, the required force proportionately increases, and these muscle forces act to increase the joint contact forces. Habitually large joint contact forces are associated with an increased risk of degenerative joint diseases such as osteoarthritis (Varady et al., 2015).

Peak forces and torques were higher in both shoulders and the lumbar back in the trial assessed to be an example of bad technique by the horticulturists and physiotherapists, when compared with the example of good efficient technique. There was also greater variability in the force and torque patterns for the bad trial relative to the good trial. It is suggested that the assessors are implicitly observing these metrics and basing their rating of the efficiency and injury risk of the action on these performance indicators.

This study explored the potential for biomechanics to contribute toward the understanding of low-risk and high-risk body positioning (or style) in relation to horticultural digging. However, it should be noted that biomechanical analysis is susceptible to the introduction of error due to motion measurement artifacts (Peters et al., 2010), muscle modeling (Ditroilo et al., 2011), and the selection of a suitable cost function minimization (Praagman et al., 2006). There were also practical limitations with the approach presented that need to be noted. By examining a range of subjects, the research attempted to establish a mean result; but, different variables such as age (Norton et al., 2010; Park et al., 2008), experience (Bridger et al., 1998), fitness (Hawkins, et al., 2011; Norton et al., 2010), and tool size (Brickell, 1992; Park et al., 2011) could potentially yield subtle differences in results. Further studies focusing on how these variables affect 
the results would be of interest. Similarly, the setup of the experiment introduced practical limitations; e.g., working in the laboratory and using an artificial soil environment made tasking each subject with exactly the same challenge difficult. Similar environmental considerations were described by Park et al. (2011). The subjects were also given space to manoeuvre freely, which in many real-world scenarios may not be the case. To optimize the accuracy of the optical tracking motion capture system in this exploratory research, these limitations were considered acceptable. It is also acknowledged that the profile of gardening experience within the sample of subjects might not be representative of the entire gardening population.

The results presented here would appear to offer an objective approach to enabling safer and more efficient actions to be defined and thus adopted by practitioners through better-informed advice, training, and awareness. In addition to digging, the approach presented here could be applied to other tasks where repeated motions could be damaging to the musculoskeletal system (e.g., hand weeding and pruning).

The results of this study, relating specifically to the task of digging, could potentially benefit both amateur and professional horticulturists. In relation to amateur horticulturists, it is suggested all ages could benefit through increased regular exercise (Park et al., 2013) and older people through extending the practice of gardening into even older age by maintaining fitness and reducing the decline in musculoskeletal function attributed to aging (Galloway and Jokl, 2000; Hawkins et al., 2011; Park et al., 2009). The benefits for professional gardeners include reducing the economic loss through lost work time, worker injuries, and insurance compensation claims. Further work across a wide range of horticultural activities would be of great value and this is currently being researched in collaboration with the Royal Horticultural Society, United Kingdom.

\section{Literature cited}

Armstrong, D. 2000. A survey of community gardens in upstate New York: Implications for health promotion and community development. Health Place 6 (4):319-327.

BoB-Biomechanics. 2016. Biomechanics of bodies (BoB). 13 June 2017. <http:// bob-biomechanics.com>.

Brickell, C.(ed.). 1992. Encyclopedia of gardening. Royal Hort. Soc./Dorling Kindersley, London, UK.

Bridger, R.S., N. Cabion, J. Goedecke, S. Rickard, E. Schabort, C. Westgarth-Taylor, and M.I. Lambert. 1997. Physiological and subjective measures of workload when shovelling with a conventional and twohandled ('levered') shovel. Ergonomics 40(11):1212-1219.

Bridger, R.S., P. Sparto, and W.S. Marras. 1998. Spade design, lumbar motions, risk of low-back injury and digging posture. Occup. Ergon. 1(3):157-172.

Buchholz, B., V. Paquet, L. Punnett, D. Lee, and S. Moir. 1996. PATH: A work sampling-based approach to ergonomic job analysis for construction and other non-repetitive work. Appl. Ergon. 27 (3):177-187.

Buck, D. 2016. Gardens and health: Implications for policy and practice. 24 Apr. 2017. <https://www.kingsfund.org.uk/ sites/files/kf/field/field_publication_ file/Gardens_and_health.pdfs.

Crowninshield, R.D., R.C. Johnston, J.G. Andrews, and R.A. Brand. 1978. A biomechanical investigation of the human hip. J. Biomech. $11(1-2): 75-85$.

Ditroilo, M., M. Watsford, A. Murphy, and G. de Vito. 2011. Assessing musculoarticular stiffness using free oscillations: Theory, measurement and analysis. Sports Med. 41(12):1019-1032.

Dunnett, N. and M. Qasim. 2000. Perceived benefits to human well-being of urban gardens. HortTechnology 10 (1):40-45.

Erdemir, A., S. McLean, W. Herzog, and A.J. van den Bogert. 2007. Model-based estimation of muscle forces exerted during movements. Clin. Biomech. (Bristol, Avon) 22(2):131-154.

Etheredge, C.L., T.M. Waliczek, and J.M. Zajicek. 2016. The influence of gardening activities on self-reported health problems, allergies, and body mass index. HortTechnology 26(6):776-782.

Filimonov, V.I., K.N. Koptsev, Z.M. Husyanov, and S.S. Nazarov. 1983. Means of increasing strength of the punch. J. Strength Cond. Res. 7(6):65-66.

Galloway, M.T. and P. Jokl. 2000. Aging successfully: The importance of physical activity in maintaining health and function. J. Amer. Acad. Orthop. Surg. 8(1):37-44.
Hallemans, A., D. De Clercq, B. Otten, and P. Aerts. 2005. 3D joint dynamics of walking in toddlers: A cross-sectional study spanning the first rapid development phase of walking. Gait Posture 22(2):107-118.

Hawkins, J.L., K.J. Thirlaway, K. Backx, and D.A. Clayton. 2011. Allotment gardening and other leisure activities for stress reduction and healthy aging. HortTechnology 21(5):577-585.

Hildebrandt, V.H. 2007. Musculoskeletal symptoms and workload in 12 branches of Dutch agriculture. J. Ergonomics 38 (12):2576-2587.

Karatsidis, A., G. Bellusci, H.M. Schepers, M. de Zee, M.S. Andersen, and P.H. Veltink. 2017. Estimation of ground reaction forces and moments during gait using only inertial motion capture. Sensors (Basel) 17(1):75.

Knibbs, L.D. 2014. Occupational hazards to the health of professional gardeners. Intl. J. Environ. Health Res. 24(6):580589.

Lauder, M. and J. Lake. 2008. Biomechanical comparison of unilateral and bilateral power snatch lifts. J. Strength Cond. Res. 22(3):653-660.

Lehmkuhl, L. and L. Smith. 1988. Brunnstrom's clinical kinesiology. F.A. Davis, Philadelphia, PA.

Lieber, R. and J. Friden. 1988. Selective damage of fast glycolytic muscle fibres with eccentric contraction of the rabbit tibialis anterior. Acta Physiol. Scand. 133 (4):587-588.

Marras, W.S., S.A. Lavender, S.E. Leurgans, S.L. Rajulu, W.G. Allread, F.A. Fathallah, and S.A. Ferguson. 1993. The role of dynamic three-dimensional trunk motion in occupationally-related low back disorders. The effects of workplace factors, trunk position, and trunk motion characteristics on risk of injury. Spine 18 (5):617-628.

Nissen, C., M. Westwell, S. Ounpuu, M. Patel, J. Tate, K. Pierz, J. Burns, and J. Bicos. 2007. Adolescent baseball pitching technique: A detailed three-dimensional biomechanical analysis. Med. Sci. Sports Exerc. 39(8):1347-1357.

Norton, K., L. Norton, and D. Sadgrove. 2010. Position statement on physical activity and exercise intensity terminology. J. Sci. Med. Sport 13(5):496-502.

Park, S.A., A.Y. Lee, H.G. Park, K.C. Son, D.S. Kim, and W.L. Lee. 2017. Gardening intervention as a low- to moderateintensity physical activity for improving blood lipid profiles, blood pressure, inflammation, and oxidative stress in 
women over the age of 70: A pilot study. HortScience 52(1):200-205.

Park, S.A., H.S. Lee, K.S. Lee, K.C. Son, and C.A. Shoemaker. 2013. The metabolic costs of gardening tasks in children. HortTechnology 23(5):589-594.

Park, S.A., K.S. Lee, and K.C. Son. 2011. Determining exercise intensities of gardening tasks as a physical activity using metabolic equivalents in older adults. HortScience 46:1706-1710.

Park, S.A. and C.A. Shoemaker. 2009. Observing body positions of older adults while gardening for health benefits and risks. Act. Adaptation Aging 33(1):31-38.

Park, S.A., C.A. Shoemaker, and M.D. Haub. 2008. Can older gardeners meet the physical activity recommendation through gardening? HortTechnology 18: 639-643.

Park, S.A., C.A. Shoemaker, and M.D. Haub. 2009. Physical and psychological health conditions of older adults classified as gardeners or nongardeners? HortScience 44:206-210

Patrick, J. 1991. Use of movement analysis in understanding abnormalities of gait in cerebral palsy. Arch. Dis. Child. 66(7): 900-903.

Perron, M., F. Malouin, H. Moffet, and B. Mcfadyen. 2000. Three-dimensional gait analysis in women with a total hip arthroplasty. Clin. Biomech. (Bristol, Avon) 15(7):504-515.
Peters, A., B. Galna, M. Sangeux, M. Morris, and R. Baker. 2010. Quantification of soft tissue artifact in lower limb human motion analysis: A systematic review. Gait Posture 31(1):1-8.

Praagman, M., E.K.J. Chadwick, F.C.T. van der Helm, and H.E.J. Veeger. 2006. The relationship between two different mechanical cost functions and muscle oxygen consumption. J. Biomech. 39(4): 758-765.

Reid, M., B. Elliott, and J. Alderson. 2007. Shoulder joint kinetics of the elite wheelchair tennis serve. Brit. J. Sports Med. 41(11):739-744

Schneider, S.P. 2001. Musculoskeletal injuries in construction: A review of the literature. Appl. Occup. Environ. Hyg. 16:11):1056-1064.

Serway, R.A. and J.W. Jewett, Jr. 2003. Physics for scientists and engineers. 6th ed. Brooks Cole, Pacific Grove, CA.

Shippen, J. and R. Ashford. 2003. Leg length measurement: Clinical versus mathematical modelling. Foot 13:174-178.

Shippen, J. and B. May. 2010. Calculation of muscle loading and joint contact forces during the rock step in Irish dance. J. Dance Med. Sci. 14(1):11-18.

Shippen, J. and B. May. 2012. The calculation of ground reaction forces during dance in the absence of forceplates. J. Dance Med. Sci. 16(1):39-43.
Shippen, J. and B. May. 2016. Constitutive kinematic modes and shapes during vehicle ingress/egress. Appl. Ergon. 56:127-135.

Solomon, C., J. Poole, K.T. Palmer, and D. Coggan. 2007. Non-fatal occupational injuries in British agriculture. Occup. Environ. Med. 64:150-154.

Sommerfield, A.J., T.M. Waliczek, and J.M. Zajicek. 2010. Growing minds: Evaluating the effect of gardening on quality of life and physical activity level of older adults. HortTechnology 20:705710 .

Sun, Y., S. Wei, Y. Zhong, W. Fu, L. Li, and Y. Liu. 2015. How joint torques affect hamstring injury risk in sprinting swing-stance transition. Med. Sci. Sports Exerc. 47(2):373-380.

Tilp, M., H. Wagner, and E. Muller. 2008. Differences in 3D kinematics between volleyball and beach volleyball spike movements. Sports Biomech. 7(3):386397.

Varady, P.A., U. Glitsch, and P. Augat. 2015. Loads in the hip joint during physically demanding occupational tasks: A motion analysis study. J. Biomech. 48(12):3227-3233.

Winter, D.A. 2004. Biomechanics and motor control of human movement. Wiley, Hoboken, NJ. 